\title{
Induction of original phenotype of human immortalized chondrocytes: A quantitative gene expression analysis
}

\author{
LIVIA ROSETI ${ }^{1}$, ANDREA FACCHINI ${ }^{1,2}$, LUCIANA DE FRANCESCHI ${ }^{1}$, \\ EMANUELE MARCONI ${ }^{1}$, EUGENE O. MAJOR ${ }^{3}$ and BRUNELLA GRIGOLO ${ }^{1}$
}

${ }^{1}$ Laboratorio di Immunologia e Genetica, Istituto di Ricerca Codivilla Putti, Istituti Ortopedici Rizzoli, Via di Barbiano 1/10, 40136 Bologna, ${ }^{2}$ Dipartimento di Medicina Interna e Gastroenterologia, Università di Bologna, Via Massarenti 9, 40138 Bologna, Italy; ${ }^{3}$ Laboratory of Molecular Medicine and Neuroscience, National Institute of Neurological Disorders and Stroke, National Institute of Health, Bethesda, MD 20892-4164, USA

Received May 15, 2006; Accepted July 7, 2006

\begin{abstract}
We previously established a line of immortalized normal human articular chondrocytes, lbpva55, expressing the E6 and E7 transforming genes of the human papilloma virus type 16 . With this study we investigated the phenotypic modulation ability of this cell line, cultured in different conditions, with the aim of validating its use for studies on cartilage metabolism and physiology. To this end, we performed a quantitative analysis, using real-time PCR technology, of the expression of the main structural components of the cartilage matrix (collagens I, II and aggrecan), of two transcription factors regulating chondrocyte differentiation (Sox-9 and Egr-1) and of some enzymes involved in matrix turnover (cathepsin B, MMP-1 and MMP-13). Results showed that, under defined conditions, lbpva55 cells were able to re-express the chondrocyte phenotype that was lost in a conventional monolayer condition, as demonstrated by an up-regulation of collagen II, the main marker of hyaline cartilage and Sox-9, a master gene regulator of chondrocytic differ-entiation. The gene expression profile of our immortalized cells compared with that of normal articular chondrocytes showed that this line could be used as a valid in vitro model for a better understanding of cell molecular mechanisms relevant for the development of new therapeutic approaches in rheumatic diseases and for the cartilage engineering field.
\end{abstract}

Correspondence to: Dr Brunella Grigolo, Laboratorio di Immunologia e Genetica, Istituto di Ricerca Codivilla Putti, I.O.R.,Via di Barbiano 1/10, 40136 Bologna, Italy

E-mail: grigolob@alma.unibo.it

Key words: immortalized chondrocytes, serum-free culture, hyaluronan-based scaffold

\section{Introduction}

The model of monolayer cultured chondrocytes has been widely used to understand the mechanisms involved in normal cartilage matrix turnover and cell differentiation and how these may be perturbed in arthritic conditions (1-3). However, detailed biochemical and molecular studies have been hampered by a number of factors such as the scarce availability of tissue and its weak cellularity. More importantly, chondrocytes expanded in monolayer display a high phenotypic instability and inherent heterogeneity within cultures (4-8). It is well known that, starting from the first passages after isolation, chondrocyte cells undergo a dedifferentiation process which involves significant changes in their phenotype and results principally in the down-regulation of collagen II and aggrecan and in the up-regulation of collagens I and III expressed in prechondrogenic mesenchymal cells (9-11). The use of chondrocytes of human origin is even more difficult due to the higher variability of the specimens (age and condition of patients) and the phenotypic liability of the cells once they are in culture, besides a number of legal and ethical problems.

In the last few years researchers have developed many alternative in vitro systems which may allow chondrocyte phenotype stabilization, such as alginate beads (12) pellet cultures (13), the use of defined media (14), growth inside three-dimensional scaffolds of different origin (15) and mechanical stimulation with bioreactors (16). These in vitro systems have been demonstrated to be effective in inducing the re-acquiring of the chondrocyte phenotype and have revealed a useful tool for researches on cartilage, but problems still remain. Chondrocyte cells maintained under conditions that enhance retention of the differentiated phenotype proliferate slower (4) and, as all cultured cells, undergo a finite number of doublings (17). To overcome these limitations, immortalized chondrocytic cell lines have been created (18). Considering the high liability of the chondrocyte phenotype, a real problem with these cell lines is the maintaining of their differentiated functions.

Recently, we developed a line of immortalized chondrocytes of human origin able to express the E6 and E7 trans- 
forming genes of the human papilloma virus type 16 (HPV-16) (19). These cells that during the monolayer expansion had lost their phenotypic pattern, were able to re-express cartilage typical markers when cultured in a serum-free defined medium and inside a hyaluronan-based biomaterial.

In order for a more in-depth investigation into the phenotypic modulation ability of the lbpva55 immortalized chondrocytes in these different culture conditions, we performed a quantitative gene expression analysis by means of real-time PCR technology. The genes evaluated were the main structural components of cartilage matrix (collagens I, II and aggrecan), two transcription factors regulating chondrocyte differentiation processes (Sox-9 and Egr-1) and some enzymes involved in matrix turn-over (Cathepsin B, MMP-1 and MMP-13). The presence of the main extra-cellular matrix molecules of cartilage was evaluated also by immunohistochemistry.

The data obtained with this study shed important light on our understanding of the biology of chondrocyte cells. The cell line that we developed could be a useful model system for studying both the metabolism of chondrocytes and their behaviour in a three-dimensional configuration which is known to modulate their phenotype.

\section{Materials and methods}

Cell line. The immortalized line of normal human articular chondrocytes (lbpva55) was established as previously described (19). Briefly, chondrocytes isolated from a multiorgan donor articular cartilage were transfected at $\mathrm{p}=0$ with a plasmid carrying the HPV-16 E6 and E7 transforming genes, with a liposome-mediated procedure. The line was developed by selecting cells for their ability to escape senescence during their expansion in monolayer.

Monolayer culture and sample preparation. The lbpva55 cells (passages 60-65), seeded at high density $\left(2 \times 10^{5}\right.$ cells $\left./ \mathrm{cm}^{2}\right)$, were cultured in Dulbecco's modified Eagle's medium (DMEM) (Gibco BRL, Grand Island, NY, USA) with $25 \mathrm{mM}$ HEPES (Sigma, St. Louis, MO, USA), 100 units/ml penicillin (Biological Industries, Israel), $100 \mu \mathrm{g} / \mathrm{ml}$ streptomycin (Biological Industries), $50 \mu \mathrm{g} / \mathrm{ml}$ gentamicin (Flow Laboratories, Biaggio, Switzerland), supplemented with $20 \%$ foetal bovine serum (FBS) (Gibco) in flasks (Costar ${ }^{\circledR}$, Cambridge, MA, USA), at $37^{\circ} \mathrm{C}$ in a humidified atmosphere of $5 \% \mathrm{CO}_{2}$. The medium was changed twice a week. At confluence, cells were trypsinized, counted by eosin exclusion dye and pelleted for real-time PCR analysis or cultured in a serum-free defined medium for fourteen days. The cells were then processed for real-time PCR or grown onto a hyaluronan-based biomaterial for thirty days and then analyzed by real-time PCR technology and immunohistochemistry. Culture times of fourteen, thirty and sixty days were chosen on the basis of previous experiments performed by our group with this immortalized line and with normal articular chondrocytes (20). For each culture condition experiments were performed in triplicate.

Serum-free conditions. Confluent monolayer lbpva55 cells (DMEM supplemented with FBS 20\%, passages 60-65) were trypsinized, plated in DMEM with $10 \%$ FCS and incubated at $37^{\circ} \mathrm{C}$ for one day. The monolayer was rinsed with Dulbecco's $\mathrm{Ca}^{2+}$ - and $\mathrm{Mg}^{2+}$-free phosphate-buffered saline (PBS) to remove serum and incubated with DMEM supplemented with 1\% Nutridoma-SP (Boehringer Mannheim Biochemicals, Indianapolis, IN, USA), a serum substitute containing insuline. Serum-free cultures were incubated for fourteen days; during this period the medium was changed twice a week and the cells were split once after eight days. At day fourteen cells were harvested and pellets processed for realtime PRC analysis.

Seeding on biomaterial. The biomaterial used as a scaffold for three-dimensional cell growth was a hyaluronan-based biopolymer termed $\mathrm{HYAFF}^{\circledR}-11$ and obtained from F.A.B. S.r.l. (FIDIA Advanced Biopolymers, Abano Terme, Italy). Immortalized lbpva55 chondrocytes under conventional monolayer culture (passages 60-65) were trypsinized and seeded onto two $1 \mathrm{~cm}^{2}$ HYAFF-11 non-woven meshes at a density of $1 \times 10^{6}$ each, in $150 \mu \mathrm{l}$ of culture medium in Petri dishes (Becton-Dickinson, Plymouth, UK). The cells were allowed to adhere for $8 \mathrm{~h}$ at $37^{\circ} \mathrm{C}$ and then $2 \mathrm{ml}$ of DMEM with $10 \%$ FBS was added. Ascorbic acid $(50 \mu \mathrm{g} / \mathrm{ml})$ was added daily only to the engineered scaffold that underwent histological staining. The medium was changed twice a week. After thirty days the scaffolds were collected and one was processed for real-time PCR, while the other was used for immunohistochemical analyses.

Real-time PRC analysis. The lbpva55 cells $\left(5 \times 10^{5}\right)$ (passages 60-65) cultured on a monolayer with DMEM supplemented with $20 \%$ FCS and with medium containing $1 \%$ NutridomaSP for fourteen days were trypsinized, pelleted and lysed in $0.5 \mathrm{ml}$ of RNAWIZ ${ }^{\mathrm{TM}}$ reagent (Ambion, Austin, TX, USA). HYAFF-11 scaffolds with seeded immortalized chondrocytes were collected after thirty days, placed in microcon 100 filtration devices and centrifuged at $1500 \mathrm{x} g$ for $5 \mathrm{~min}$ in order to remove the liquid medium. Cells were lysed directly in the culture scaffold by the addition of $0.5 \mathrm{ml}$ of RNAWIZ reagent.

Total RNA was subsequently isolated from the samples using the single-step guanidinium thiocyanate-phenolchloroform method. Complementary DNA was synthesized from $1 \mu \mathrm{g}$ of total RNA per sample with 45-min incubation at $42^{\circ} \mathrm{C}$, using Moloney Murine leukemia virus reverse transcriptase (Perkin Elmer, Norwalk, CT, USA) and oligo-(dT) priming. PCR primers for aggrecan and for the housekeeping gene glyceraldehyde-3-phosphate dehydrogenase (GAPDH), used as endogenous control, were obtained from published references $(21,22)$. PCR primers for cathepsin B, collagens I and II, Egr-1, MMP-1, MMP-13 and Sox-9, were designed by our group (23-25).

Real-time PCR was run in a LightCycler instrument (Roche Molecular Biochemicals, Mannheim, Germany) using the QuantiTect ${ }^{\mathrm{TM}} \mathrm{SYBR}^{{ }^{\circledR}}{ }_{-}$Green PCR kit (Qiagen, $\mathrm{GmbH}$, Germany). Cycling parameters were: $15 \mathrm{~min}$ at $94^{\circ} \mathrm{C}$ (initial activation of HotStarTaq ${ }^{\mathrm{TM}}$ DNA polymerase) followed by 45 cycles of $15 \mathrm{sec}$ at $94^{\circ} \mathrm{C}, 20 \mathrm{sec}$ at $56^{\circ} \mathrm{C} / 58^{\circ} \mathrm{C} / 60^{\circ} \mathrm{C}$ (depending on primer pair) and $10 \mathrm{sec}$ at $72^{\circ} \mathrm{C}$. The increase in PCR product was monitored for each amplification cycle 
by measuring the increase in fluorescence caused by the binding of SYBR-Green I dye to dsDNA. The threshold cycle $\left(\mathrm{C}_{\mathrm{T}}\right)$ values (i.e. the cycle numbers at which the detected fluorescence reaches a threshold value in the range of exponential amplification) were determined for each sample and specificity of the amplicons was confirmed by melting curve analysis and agarose gel electrophoresis. To analyze data from real-time PCR we used the 'comparative $\mathrm{C}_{\mathrm{T}}$ method' previously described by Livak (26). As a relative quantification method, it relates the PCR signal of each target gene obtained in the samples (or sample groups) to that of a reference control (or reference control group) using the formula $2^{-\triangle \Delta C T}$. In this case the monolayer cultured immortalized lbpva55 cells were considered the control group and the cells cultured in serum-free conditions for fourteen days and grown inside the HYAFF-11 biomaterial for thirty days were the sample groups. For each sample, $\Delta \mathrm{C}_{\mathrm{T}}$ represents the difference between $\mathrm{C}_{\mathrm{T}}$ of each target gene and the internal control gene (GAPDH). For each specific gene $\Delta \Delta \mathrm{C}_{\mathrm{T}}$ represents the difference between $\Delta \mathrm{C}_{\mathrm{T}}$ of the different samples and the control. For each control sample $\Delta \Delta C_{T}=0$ and $2^{0}=1$, by definition. Using this method, the data are presented as differences in gene expression (relative gene expression) normalized to an endogenous reference gene and relative to a control group.

Statistical analysis. Statistical computations were performed using CSS Statistica-Statistical software (Statsoft Inc. Tulsa, OK, USA). All values were expressed as the mean \pm standard deviation (SD). Quantitative parameters were compared by means of the Wilcoxon matched pairs non-parametric test. Differences were considered as significant when $\mathrm{p}<0.05$.

Immunohistochemistry. For immunohistochemical analysis the following primary antibodies were used: mouse monoclonal anti-human collagen type I (Chemicon International, Temecula, CA, USA), mouse monoclonal anti human collagen type II (Chemicon International), mouse monoclonal anti-human proteoglycans (Chemicon International) and goat affinity purified polyclonal anti-human cathepsin B (Santa Cruz Biotechnology, Inc.). HYAFF-11 engineered scaffolds were embedded in OCT and snap-frozen in liquid nitrogen. The specimens were then sectioned into $5-\mu \mathrm{m}$ sections, air dried and stored at $-80^{\circ} \mathrm{C}$. At analysis the slides were transferred at room temperature, air dried for $15 \mathrm{~min}$ and fixed in methanol/acetone at $4^{\circ} \mathrm{C}$ for 20 and 10 min respectively. Airdried fixed samples were rehydrated and, for epitope unmasking, were treated with $0.1 \%$ hyaluronidase (Sigma) in phosphate buffered saline (PBS) at $37^{\circ} \mathrm{C}$ for $5 \mathrm{~min}$. After washing, for the detection of type I and II collagens the slides were incubated at room temperature for $30 \mathrm{~min}$ in X1 PBS containing 5\% normal goat serum (NGS) (Dako, Carpinteria, CA, USA), while normal rabbit serum (NRS) (Dako) was used for cathepsin $\mathrm{B}$, to prevent non-specific binding. The slides were incubated with anti-human collagen type I, collagen type II, proteoglycans and cathepsin B, primary antibodies diluted 1:20,1:20, 1:50 and 1:200 respectively in $0.04 \mathrm{M}$ Trizma base saline (TBS), $\mathrm{pH} 7.6$, containing $1 \%$ bovine serum albumin (BSA) and $0.1 \%$ Triton X-100 for $1 \mathrm{~h}$ at room temperature. For the detection of type I and II
$\mathbf{A}$

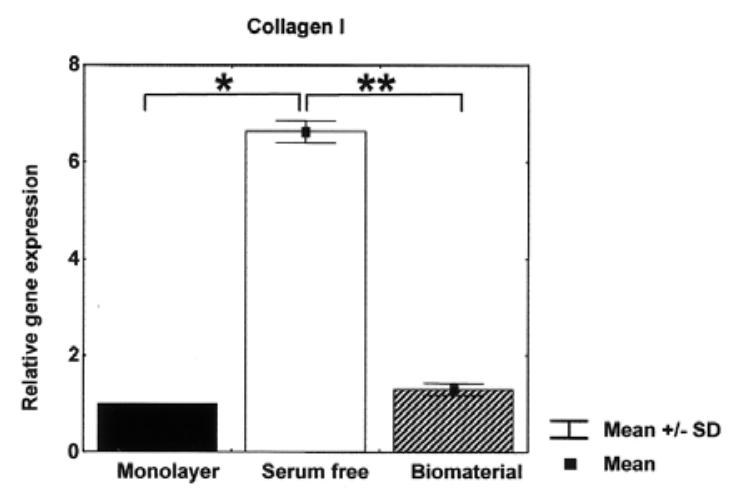

B

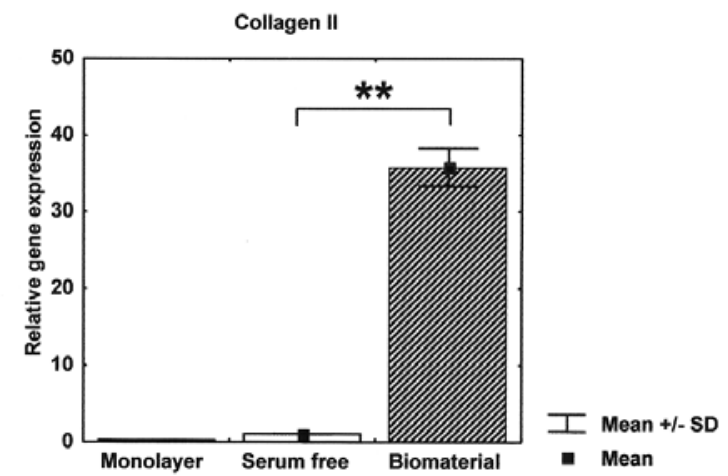

C

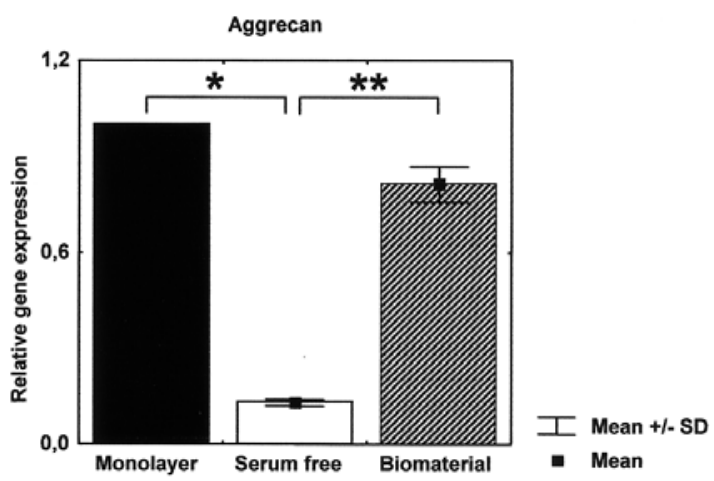

Figure 1. Quantitative real-time PCR analysis of differential gene expression levels of collagen I (A), collagen II (B) and aggrecan (C) in immortalized chondrocytes (lbpva55 line) cultured in a conventional monolayer condition, in serum-free cultures (14 days) and grown onto HYAFF-11 biomaterial (30 days). Results are reported as relative gene expression and calculated by the formula $2^{-\triangle \Delta C T}$. The $2^{-\triangle \Delta C T}$ value represents the difference between $C_{T}$ of each target gene and the internal control (GAPDH). The $\Delta \Delta \mathrm{C}_{\mathrm{T}}$ value for each specific gene represents the difference between $\Delta C_{T}$ values for all the experimental times evaluated and the $\Delta \mathrm{C}_{\mathrm{T}}$ value obtained on day 1 . Using this method, the $\Delta \Delta \mathrm{C}_{\mathrm{T}}$ value obtained on day $1=$ zero and $2^{0}=1$, by definition. Monolayer vs serum free, ${ }^{*} \mathrm{p}<0.05$; serum free vs biomaterial, $* * \mathrm{p}<0.05$; monolayer vs biomaterial, ***p $<0.05$. Values are expressed as mean \pm standard deviation (SD).

collagens and proteoglycans slides were washed three times with $0.04 \mathrm{M}$ TBS, $\mathrm{pH} 7.6$, and incubated with goat antimouse and anti-rabbit immunoglobulins labelled with dextran molecules-alkaline phosphatase (Dako) at room temperature for $30 \mathrm{~min}$. For cathepsin B immunostaining anti-goat-biotin conjugated rabbit immunoglobulins (Pierce, Rockford, IL, USA) diluted 1:200 in TBS 0.04 M, pH 7.6, 
A

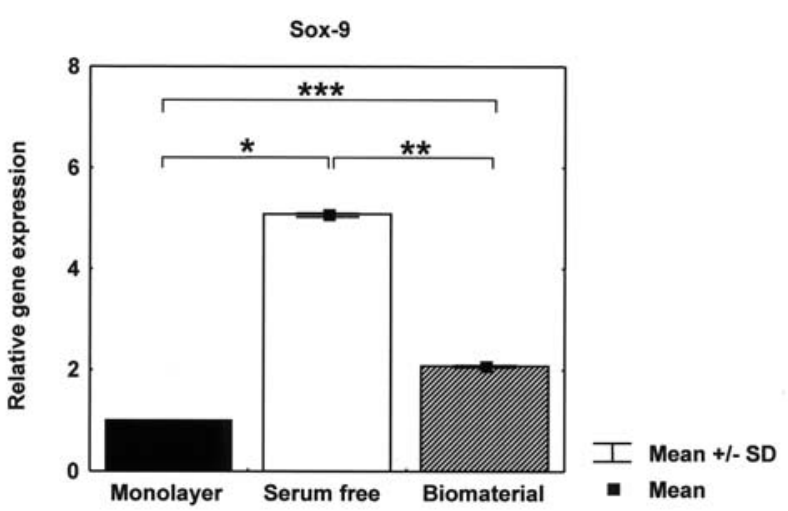

B

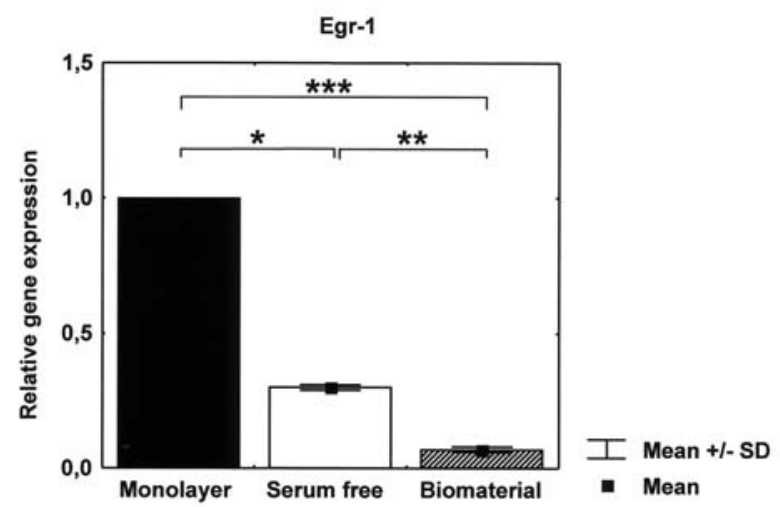

Figure 2. Quantitative real-time PCR analysis of differential gene expression levels of Sox-9 (A) and Egr-1 (B) in immortalized chondrocytes (lbpva55 line) cultured in conventional monolayer condition, in serum-free cultures (14 days) and grown onto HYAFF-11 biomaterial (30 days). Results are reported as relative gene expression and calculated by the formula $2^{-\Delta \Lambda C T}$. The $\Delta \mathrm{C}_{\mathrm{T}}$ value represents the difference between $\mathrm{C}_{\mathrm{T}}$ of each target gene and the internal control (GAPDH). The $\Delta \Delta \mathrm{C}_{\mathrm{T}}$ value for each specific gene represents the difference between $\Delta \mathrm{C}_{\mathrm{T}}$ values for all the experimental times evaluated and the $\Delta C_{T}$ value obtained on day 1 . Using this method, the $\Delta \Delta C_{T}$ value obtained on day $1=$ zero and $2^{0}=1$, by definition. Monolayer vs serum free, ${ }^{*} \mathrm{p}<0.05$; serum free vs biomaterial, $* * \mathrm{p}<0.05$; monolayer vs biomaterial, ${ }^{* * * *} \mathrm{p}<0.05$. Values are expressed as mean \pm standard deviation (SD).

were used and a further incubation of $1 \mathrm{~h}$ at room temperature with a streptavidin-alkaline phosphatase conjugate (Boehringer) was also performed. After three washes with $0.04 \mathrm{M}$ TBS, $\mathrm{pH} 7.6$, the reactions were developed using a new fucsin kit (kit new fucsin substrate system, Dako) in the presence of $5 \mathrm{mM}$ levamisole (Sigma) to block endogenous alkaline phosphatase. Negative controls were performed by omitting the primary antibody. Slides were counterstained with hematoxylin and mounted in glycerol gel. All the samples were analysed using a Zeiss axioscope microscope (Carl Zeiss, Oberkochen, Germany).

\section{Results}

Real-time PCR analysis. Real-time PCR results, calculated using the $\Delta \mathrm{C}_{\mathrm{T}}$ method as described in Materials and methods,
$\mathbf{A}$

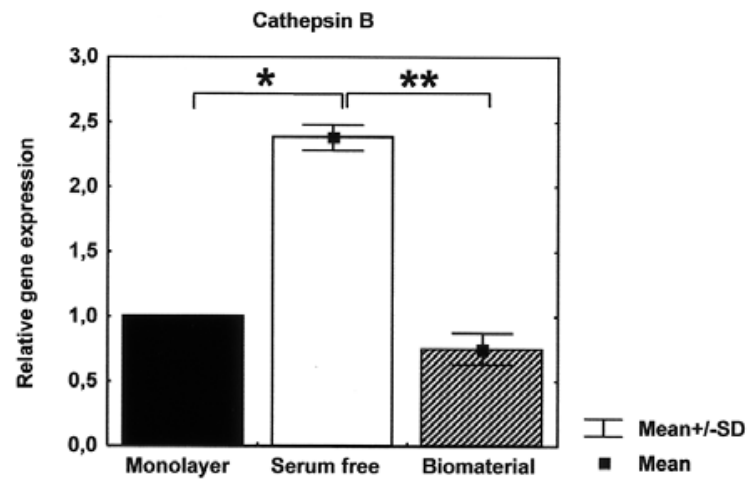

B

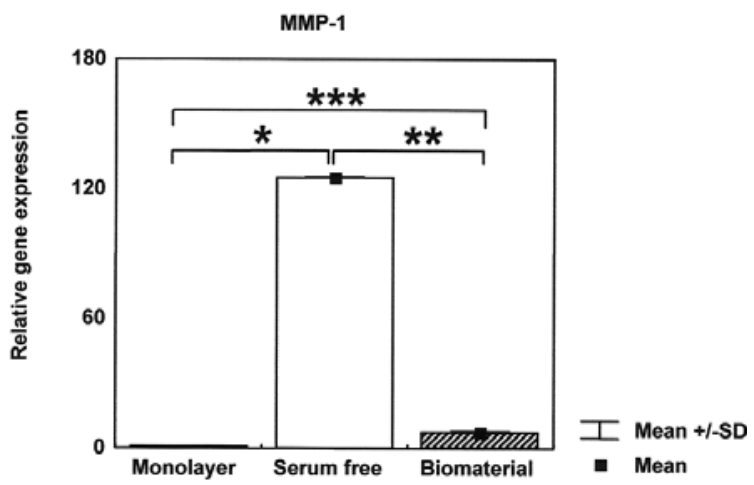

C

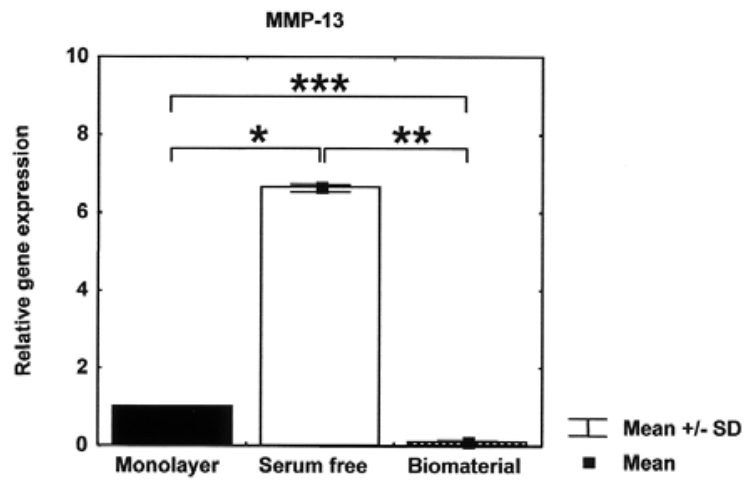

Figure 3. Quantitative real-time PCR analysis of differential gene expression levels of cathepsin B (A), MMP-1 (B) and MMP-13 (C) in immortalized chondrocytes (lbpva55 line) cultured in conventional monolayer condition, in serum-free cultures (14 days) and grown onto HYAFF-11 biomaterial (30 days). Results are reported as relative gene expression and calculated by the formula $2^{-\Delta \Delta C T}$. The $\Delta \mathrm{C}_{\mathrm{T}}$ value represents the difference between $\mathrm{C}_{\mathrm{T}}$ of each target gene and the internal control $(\mathrm{GAPDH})$. The $\Delta \Delta \mathrm{C}_{\mathrm{T}}$ value for each specific gene represents the difference between $\Delta \mathrm{C}_{\mathrm{T}}$ values for all the experimental times evaluated and the $\Delta \mathrm{C}_{\mathrm{T}}$ value obtained on day 1 . Using this method, the $\Delta \Delta C_{T}$ value obtained on day $1=$ zero and $2^{0}=1$, by definition. Monolayer vs serum free, ${ }^{*} \mathrm{p}<0.05$; serum free vs biomaterial, $* * \mathrm{p}<0.05$; monolayer vs biomaterial, $* * * p<0.05$. Values are expressed as mean \pm standard deviation (SD).

and evaluted as relative gene expression, are shown in Figs. 1-3. Collagen I mRNA was detected in all the culture conditions evaluated. Its expression showed a significant increase in the chondrocytes cultured under serum-free conditions in comparison to the cells expanded in monolayer (6.6-fold) and 


\section{Collagen II}

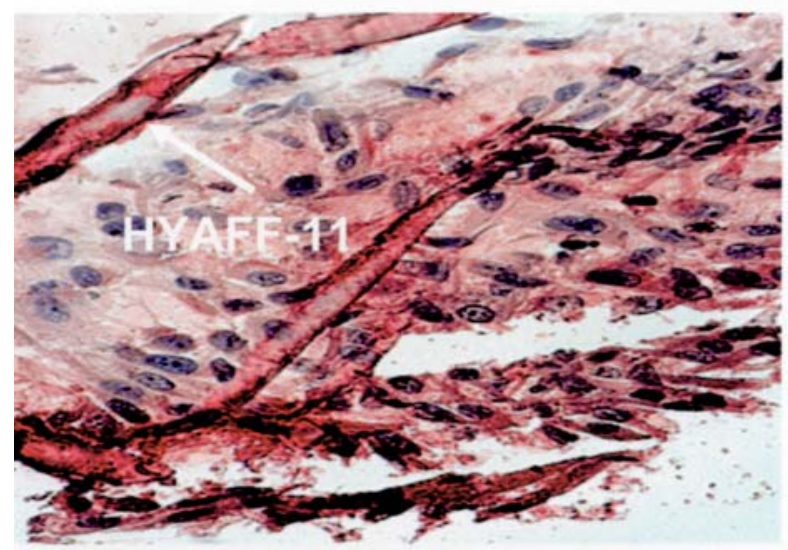

Proteoglycans

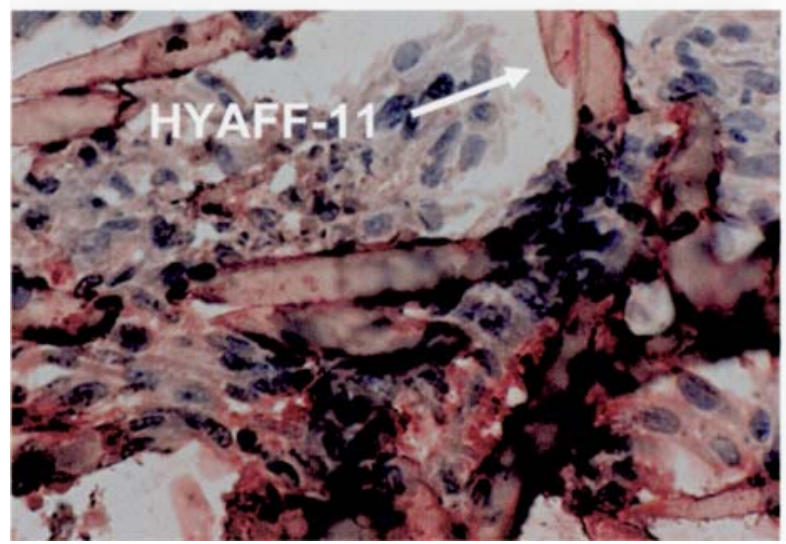

Collagen I

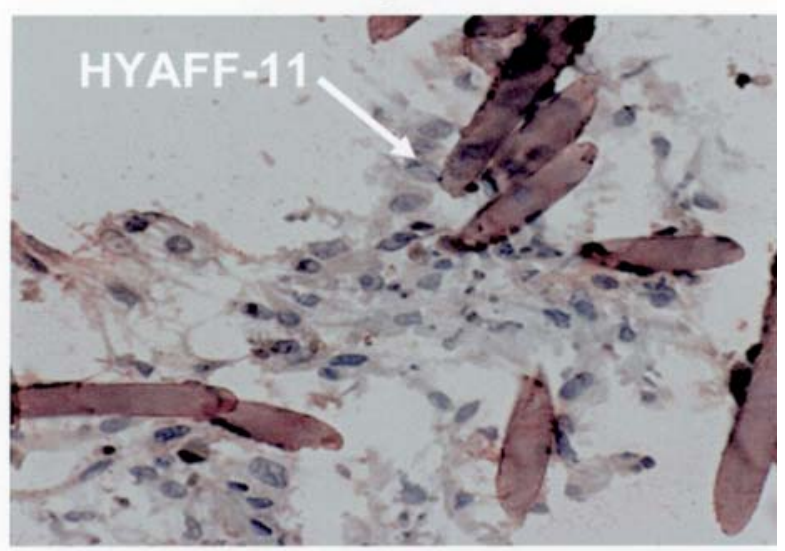

Cathepsin B

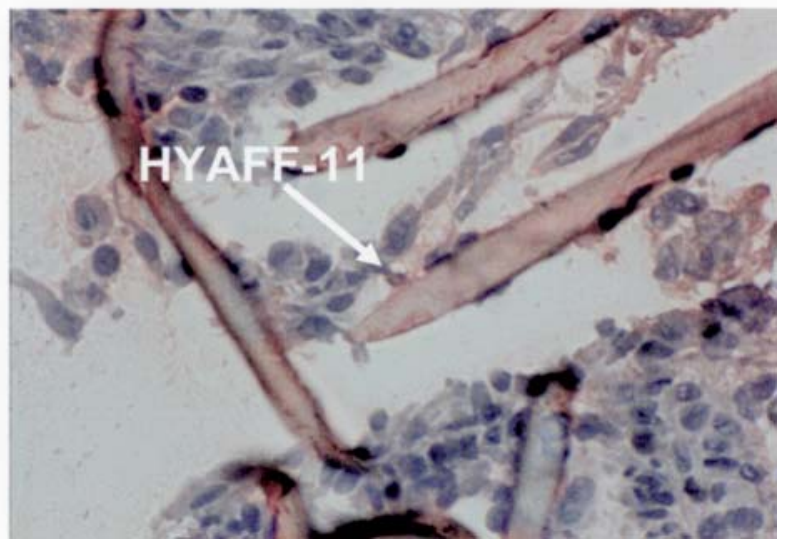

Figure 4. Collagen II (lef upper panel), collagen I (right upper panel), proteoglycans (left lower panel) and cathepsin B (right lower panel) immunostaining of immortalized chondrocytes (lbpva55) seeded on HYAFF-11 at day 60. All samples were developed using new fucsin (red, positive stain). HYAFF-11 fibers are indicated with white arrows.

grown onto the biomaterial (5.1-fold). Values were slightly higher ( 0.3 fold difference) for the HYAFF-11 engineered cells compared to the monolayer condition (Fig. 1A). Collagen II mRNA was undetectable in the monolayer cultured chondrocytes. For this reason, the $\Delta \mathrm{C}_{\mathrm{T}}$ analysis for this gene was performed comparing only the serum-free and the scaffold cultures. The results showed that, when the cells were cultured in the two re-differentiating conditions tested, they started to re-express collagen II mRNA and that its levels were significantly higher (35.8-fold) for the HYAFF-11 cultures compared to the Nutridoma-SP ones (Fig. 1B). Aggrecan mRNA was present in all the culture models studied. In comparison with the monolayer cultured cells, it showed a decrease that was significant (7-fold) in serum-free condition and slight (1.2-fold) for the engineered scaffolds. Gene expression levels were significantly lower in Nutridoma-SP compared to the biomaterial cultures (5-fold) (Fig. 1C). Sox9 mRNA was expressed in the monolayer condition and showed a significant increase both in the Nutridoma-SP (5.1fold) and in the HYAFF-11 (2.1-fold) cultures. Its values were significantly higher (2.4-fold) in serum-free cultured chondrocytes in comparison with the engineered ones (Fig. 2A). Egr-1 expression significantly decreased in serum-free conditions (3.4-fold) and in the engineered scaffolds (16.6- fold) in comparison with the monolayer cultured chondrocytes. Values were significantly higher (4.8-fold) for the cells cultured with Nutridoma-SP compared to the ones grown inside the biomaterial (Fig. 2B). Cathepsin B, MMP-1 and MMP-13 mRNAs were detected in all the experimental conditions evaluated (Fig. 3A, B and C, respectively). Their expression was significantly higher in the serum-free cultures both in comparison with the monolayer ones (2.4-, 125- and 6.6-fold, respectively) and with the HYAFF-11 engineered chondrocytes (3.2-, 16.8- and 55-fold, respectively). For the cells cultured onto the biomaterial values were lower for cathepsin B (1.3-fold), significantly lower (8.3-fold) for MMP-13 and significantly higher for MMP-1 (7.4-fold), in comparison with the monolayer cultures.

Immunohistochemical analysis. To verify the re-acquisition of the chondrocyte phenotype in the immortalized engineered scaffolds, the production of collagens II and I, proteoglycans and cathepsin B was evaluated by immunohistochemistry (Fig. 4). The analyses, performed after thirty days of culture, showed a strong positivity for collagen type II, while collagen type I was completely undetectable. The occurrence of a redifferentiation process was also confirmed by an evident matrix staining for proteoglycans and a weak positivity for cathepsin B. 


\section{Discussion}

Studies with articular chondrocytes have been hampered by the high instability of the cartilage-specific phenotype when cells are cultured in monolayer (4-8). Among the various directions that have been explored to overcome this limitation, the generation of stable lines of immortalized chondrocytes is becoming more and more a reality, due also to improvements in the transformation protocols which have allowed the creation of immortalized cells from pathologic tissue (18).

We previously established a line of immortalized normal human articular chondrocytes, lbpva55, expressing the E6 and E7 transforming genes of the HPV-16 (19). These cells lost their phenotypic pattern during the monolayer expansion, but demonstrated the ability to re-express the main cartilage markers when cultured in a serum-free defined medium and inside a three-dimensional scaffold, two culture models which were known to allow chondrocyte re-differentiation $(14,15)$. In fact, we chose a serum substitute already used for immortalized chondrocytes (27) and containing insulin which may replace insulin-like growth factor-I (IGF-I), an anabolic growth factor involved in the maintenance of articular cartilage phenotypic expression $(28,29)$. As a scaffold for the cells we chose a hyaluronan-based three-dimensional biomaterial, HYAFF-11, which had been previously used by our group for chondrocyte transplantation in rabbits (30) and tested for its ability to allow the in vitro re-differentiation of normal human cartilage cells (20). The clinical use of this scaffold in the autologous chondrocyte transplantation procedure for the repair of cartilage defects in humans is well documented $(31,32)$.

In order to investigate the phenotypic modulation ability of the immortalized chondrocytes in more depth, we performed a quantitative real-time PCR analysis which allowed the quantification of the differences in gene expression between the cells cultured in monolayer and in these two redifferentiating conditions.

The results of the present study indicate that HYAFF-11 is more suitable in inducing the re-differentiation process in accordance with those obtained by our group with the same biomaterial seeded with normal human articular chondrocytes (20). This is confirmed by the expression of cartilage markers and by the presence of specific transcription factors such as Sox-9 and Egr-1 which are known to be involved in the modulation of chondrocyte phenotypic gene expression. Sox-9 is a member of the family of Sox (Sry-type highmobility group box transcription factor) genes and contains a high mobility group DNA-binding domain (33). It has been demonstrated to play an essential role in the commitment of mesenchymal cells to the chondrogenic lineage and in the process of chondrocyte differentiation. Its presence is required for the expression of a series of chondrocytespecific marker genes including collagen II and aggrecan (34). However, its role has not been throughly clarified (35). What was surprising for us was that Sox-9 mRNA levels were higher in the Nutridoma-SP cultures than in the HYAFF-11 cultures where collagen II and aggrecan levels were significantly greater. A lack of positive correlation between Sox-9 and collagen II expression has been already demonstrated in adult human articular chondrocytes (37). Moreover, some authors (36) found that the overexpression of Sox-9 induces an inhibition of collagen II in rabbit articular chondrocytes. The early growth response (Egr-1) transcription factor belongs to the class of immediate early genes (35). It is a serum-inducible zinc finger protein that has been demonstrated to be crucial in the regulation of growth factors, hormones, cytokines and adhesion molecules (38). It has been shown that Egr-1 is highly expressed in primary human articular chondrocytes (39) and lower expression levels have been found in osteoarthritic cartilage (40). However, the role of Egr-1 remains controversial, since it can act both as a transcriptional activator and as a suppressor (38) and target genes in chondrocyte differentiation have not been well identified. Egr-1 has been suggested to serve as a transcriptional suppressor for collagen II by preventing interactions between $\mathrm{Sp} 1$ and the transcriptional machinery (41). This finding is in accordance with our results: higher levels in the monolayer cultures where no collagen II expression was detected and decreased levels both in the serum-free and in the scaffold cultures, thus confirming a reactivation of the transcriptional mechanisms involved in chondrocyte differentiation. Moreover, since it is known that Egr-1 is transiently induced by serum (42), the higher levels observed in the immortalized chondrocytes cultured in monolayer are likely to be due to the presence of $20 \%$ FBS in the medium. In fact, these levels decreased in the scaffold cultures where FBS was present at a $10 \%$ concentration and in serum-free conditions where serum was completely depleted. However, mRNA levels were significantly higher in the Nutridoma-SP cultures compared with the HYAFF-11 cultures. This could be attributed to the reported ability of insulin to induce Egr-1 expression (43).

Finally, we analyzed the expression of two cartilage matrix metalloproteinases (MMPs), fibroblast collagenase (MMP-1) and collagenase 3 (MMP-13), which are members of a large family of proteinases that have several structural features in common, including the presence of a conserved zinc-binding catalytic domain (44). In particular, MMP-1 and -13 which are able to degrade native triple-helical collagen by cleaving at the collagenase site, have been demonstrated to play a major pathological role in the cartilage destruction of osteoarthritis (45). We found that the gene expression levels of the two MMPs were detectable in all the culture conditions evaluated, as already observed in vitro for both normal and immortalized human articular chondrocytes $(46,47)$. A significant up-regulation was observed in the Nutridoma-SP cultures, while the engineered cells displayed lower levels. The ability of the hyaluronan-based HYAFF-11 scaffold to reduce the expression of molecules involved in cartilage degeneration in normal human articular chondrocytes has been already demonstrated by our group (25). It seems that the lbpva55 cells also benefit from the presence of the hyaluronan molecule that operates on chondrocyte metabolism activating anabolic pathways (48).

Since our experiments were performed under static conditions, further studies need to be conducted in a mechanically active environment such as a bioreactor. Bioreactors have become an important tool for tissue engineering as they provide both the technological means to 
reveal the fundamental mechanisms of cell function in a three-dimensional environment, and the potential to improve the quality of engineered tissues (49). Particularly, it would be interesting to evaluate of the differences in gene expression of immortalized human chondrocyte cells under different physical stimula.

\section{Acknowledgments}

We thank Patrizia Rappini and Graziella Salmi for assistance in the preparation of the manuscript and Luciano Pizzi for his technical assistance. We also thank Mr. Keith Smith for revising the paper.

\section{References}

1. Green WT: Behaviour of articular chondrocytes in cell culture. Clin Orthop 75: 248-260, 1971.

2. Goldring MB: Human chondrocyte cultures as models of cartilage-specific gene regulation. Methods Mol Med 107: 69-96, 2004.

3. Goldring MB: Culture of immortalized chondrocytes and their use as models of chondrocyte function. Methods Mol Med 100: 37-52, 2004.

4. Kolettas E, Buluwela L, Bayliss MT and Muir HI: Expression of cartilage-specific molecules is retained on long-term culture of human articular chondrocytes. J Cell Sci 108: 1991-1995, 1995.

5. Archer C, McDowell J, Bayliss M, Stephens M and Bentley G: Phenotypic modulation of sub-populations of human articular chondrocytes in vitro. J Cell Sci 97: 361-371, 1990.

6. Swoboda B, Holmdahl R, Stoss H and von der Mark K: Cellular heterogeneity in cultured human chondrocytes identified by antibodies specific for alpha 2(XI) collagen chains. J Cell Biol 109: 1363-1369, 1989.

7. Aulthouse AL, Beck M, Griffey E, Sanford J, Arden K, Machado MA, Aulthouse AL, Ahmed S and Ellard JT: Expression of the human chondrocyte phenotype in vitro. In Vitro Cell Dev Biol 25: 659-668, 1989.

8. Baici A, Lang A, Hörler D and Knöpfel M: Cathepsin B as a marker of the dedifferentiated chondrocyte phenotype. Ann Rheum Dis 47: 684-691, 1988.

9. Benya PD, Padilla SR and Mimni ME: Independent regulation of collagen types by chondrocytes during the loss of differentiated function in culture. Cell 15: 1313-1321, 1978.

10. von der Mark K, Gauss V, von der Mark H and Muller P: Relationship between cell shape and type of collagen synthesised as chondrocytes lose their cartilage phenotype in culture. Nature 267: 531-532, 1977.

11. Darling EM and Athanasion KA: Rapid phenotypic changes in passaged articular chondrocyte subpopulations. J Orthop Res 23: 425-432, 2005.

12. Grandolfo P, D'Andrea P, Paoletti M, Martina M, Silvestrini E, Bonucci $\mathrm{E}$ and Fittur F: Culture and differentiation of chondrocytes entrapped in alginate beads. Calcif Tissue Int 52: 42-48, 1993.

13. Zhang Z, McCaffery JM, Spencer RG and Francomano CA: Hyaline cartilage engineered by chondrocytes in pellet culture: histological, immunohistochemical and ultrastructural analysis in comparison with cartilage explants. J Anat 205: 229-237, 2004.

14. Taub M: The use of defined media in cell and tissue culture. Toxic in Vitro 4: 213-225, 1989.

15. Freed L. Marquis JC, Nohria A, Emmanual J, Mikos AG and Langer R: Neocartilage formation in vitro and in vivo using cells cultured on synthetic biodegradable polymers. J Biomed Mat Res 27: 11-23, 1993.

16. Lee DA and Martin I: Bioreactor culture techiques for cartilage tissue engineering. Methods Mol Biol 238: 159-170, 2004.

17. Haudenschild DR, McPherson JM, Tubo R and Binette F: Differential expression of multiple genes during articular chondrocyte redifferentiation. Anat Rec 263: 91-98, 2001.

18. Yoshimatsu T, Saitoh A, Ryu JN, Shima D, Handa H, Hiramoto M, Kawakami Y and Aizawa S: Characterization of immortalized human chondrocytes originated from osteoarthritis cartilage. Int J Mol Med 8: 345-351, 2001.
19. Grigolo B, Roseti L, Neri S, Gobbi P, Jensen P, Major EO and Facchini A: Human articular chondrocytes immortalized by HPV-16 E6 and E7 genes: Maintenance of differentiated phenotype under defined culture conditions. Osteoarthritis Cartilage 10: 879-889, 2002.

20. Grigolo B, Lisignoli G, Piacentini A, Fiorini M, Gobbi P, Mazzotti G, Duca M, Pavesio A and Facchini A: Evidence for redifferentiation of human chondrocytes grown on a hyaluronanbased biomaterial (Hyaff-11): molecular, immunohistochemical and ultrastructural analysis. Biomaterials 3: 1187-1195, 2001.

21. Martin I, Jakob M, Schäfer D, Dick W, Spagnoli G and Heberer M: Quantitative analysis of gene expression in human articular cartilage from normal and osteoarthritic joints. Ostearthritis Cartilage 9: 112-118, 2001

22. Blanco FJ, Geng Y and Lotz M: Differentiation-dependent effects of IL- 1 and TGF- $\beta$ on human articular chondrocyte proliferation are related to inducible nitric oxide synthase expression. J Immunol 154: 4018-4026, 1995.

23. Grigolo B, Roseti L, Fiorini M, Piacentini A, De Franceschi L and Facchini A: Cathepsin B as a soluble marker to monitor the phenotypic stability of engineered cartilage. Biomaterials 24: 1751-1757, 2003.

24. Grigolo B, Roseti L, De Franceschi L, Piacentini A, Cattini L, Manfredini M, Faccini R and Facchini A: Molecular and immunohistological characterization of human cartilage two years following autologous cell transplantation. J Bone Joint Surg Am 87: 46-57, 2005.

25. Grigolo B, De Franceschi L, Roseti L, Cattini L and Facchini A: Down regulation of degenerative cartilage molecules in chondrocytes grown on a hyluronan-based scaffold. Biomaterials 26 : 5668-5676, 2005.

26. Livak KJ and Schmittgen TD: Analysis of relative gene expression data using Real-Time quantitative PCR and the $2^{-\Delta \Delta C T}$ method. Methods 25: 402-408, 2001.

27. Goldring MB, Birkhead JR, Suen LF, Yamin R, Mizuno S, Glowacki J, Arbiser JL and Apperley JF: Interleukin-1B modulated gene expression in immortalized human chondrocytes. J Clin Invest 94: 2307-2316, 1994.

28. Fortier LA, Deak MM, Semevolos SA and Cerione RA: Insulinlike growth factor-I diminishes the activation status and expression of the small GTPase Cdc 42 in articular chondrocytes. J Orthop Res 22: 436-445, 2004.

29. Loeser RF, Pacione CA and Chubinskaya S: The combination of insulin-like growth factor 1 and osteogenic protein 1 promotes increased survival of and matrix synthesis by normal and osteoarthritic human articular chondrocytes. Arthritis Rheum 48: 2188-2196, 2003.

30. Grigolo B, Roseti L, Fiorini M, Fini M, Giavaresi G, Nicoli Aldini N, Giardino R and Facchini A: Transplantation of chondrocytes seeded on a hyaluronan derivative (Hyaff $\left.{ }^{\circledR}-11\right)$ into cartilage defects in rabbits. Biomaterials 22: 2417-2424, 2001.

31. Marcacci M, Zaffagnini S, Kon E, Visani A, Iacono F and Loreti L: Arthroscopic autologous chondrocyte transplantation: technical note. Knee Surg Sports Traumatol Arthrosc 10: 154-159, 2002.

32. Marcacci M, Berruto M, Brocchetta D, Delcogliano A, Ghinelli D, Gobbi A, Kon E, Pederzini L, Rosa D, Sacchetti DL, Stefani G and Zanasi S: Articular cartilage engineering with Hyalograft $C$ : 3-year clinical results. Clin Orthop 435: 96-105, 2005.

33. Davies SR, Sakano S, Zhu Y and Sandell LJ: Distribution of the transcription factors SOX9, AP-2, and [delta]EF1 in adult murine articular and meniscal cartilage and growth plate. J Histochem Cytochem 50: 1059-1065, 2002.

34. Sekiya I, Tsuji K, Koopman P, Watanabe H, Yamada Y, Shinomiya K, Nifuji A and Noda M: SOX9 enhances aggrecan gene promotor/enhancer activity and is up-regulated by retinoic acid in a cartilage-derived cell TC6. J Biol Chem 275: 10738-10744, 2000.

35. Aigner T, Gebhard PM, Schmid E, Bau B, Harley V and Poschl E: SOX9 expression does not correlate with type II collagen expression in adult articular chondrocytes. Matrix Biol 22: 363-372, 2003.

36. Kypriotou M, Fossard-Demoor M, Chadjichristos C, Ghayor C, de Crombrugghe B, Pujol JP and Galera P: SOX9 exerts a bifunctional effect on type II collagen gene (COL2A1) expression in chondrocytes depending on the differentiation state. DNA Cell Biol 22: 19-29, 2003.

37. Sukhatme VP, Kartha S, Toback FG, Taub R, Hoover RG and Tsai-Morris CH: A novel early growth response gene rapidly induced by fibroblast, epithelial cell and lymphocyte mitogens. Oncogene Res 1: 343-355, 1987. 
38. Khachigian LM and Collins T: Early growth response factor 1: a pleiotropic mediator of inducible gene expression. J Mol Med 76: 613-616, 1998.

39. Schnabel M, Marlovits S, Eckhoff G, Fichtel I, Gotzen L, Vecsei V and Schlegel J: Dedifferentiation-associated changes in morphology and gene expression in primary human articular chondrocytes in cell culture. Osteoarthritis Cartilage 10: 62-70, 2002.

40. Wang FL, Connor JR, Dodds RA, James IE, Kumar S, Zou C, Lark MW, Gowen M and Nuttall ME: Differential expression of Egr-1 in osteoarthritic compared to normal adult human articular cartilage. Osteoarthritis Cartilage 8: 161-169, 2000.

41. Tan L, Peng H, Osaki M, Choy BK, Auron PE, Sandell LJ and Goldring MB: Egr-1 mediates transcriptional repression of COL2A1 promoter activity by interleukin-1beta. J Biol Chem 278: 17688-17700, 2003.

42. Christy BA, Lau LF and Nathans D: A gene activated in mouse 3T3 cells by serum growth factors encodes a protein with 'zinc finger' sequences. Proc Natl Acad Sci USA 85: 7857-7861, 1988.

43. Sukhatme VP, Cao XM, Chang LC, Tsai-Morris $\mathrm{CH}$, Stamenkovich D, Ferreira PC, Cohen DR, Edwards SA, Shows TB and Curran T: A zinc finger-encoding gene coregulated with c-fos during growth and differentiation, and after cellular depolarisation. Cell 3: 37-43, 1988.
44. Nagase H and Woessner JF Jr: Matrix metalloproteinases. J Biol Chem 274: 21491-21494, 1999.

45. Murphy G, Knauper V, Atkinson S, Butler G, English W, Hutton M, Stracke J and Clark I: Matrix metalloproteinases in arthritic disease. Arthritis Res 4: S39-S49, 2002.

46. Bau B, Gebhard PM, Haag J, Knorr T, Bartnik E, Aigner T: Relative messenger RNA expression profiling of collagenases and aggrecanases in human articular chondrocytes in vivo and in vitro. Arthritis Rheum 46: 2648-2657, 2002.

47. Robbins JR, Thomas B, Tan L, Choy B, Arbiser JL, Berenbaum F and Goldring MB: Immortalized human adult articular chondrocytes maintain cartilage-specific phenotype and responses to interleukin-13. Arthritis Rheum 43: 2189-2201, 2000.

48. Knudson CB and Knudson W: Hyaluronan and CD44: modulators of chondrocyte metabolism. Clin Orthop 427: S152S162, 2004.

49. Démarteau O, Jakob M, Schäfer D, Heberer M and Martin I: Development and validation of a bioreactor for physical stimulation of engineered cartilage. Biorheology 403: 331-336, 2003. 